\title{
ANTIBACTERIAL ACTIVITY OF THREE PLANT EXTRACTS AGAINST MULTIDRUG RESISTANCE PSEUDOMONAS AERUGINOSA
}

\author{
YASSIR HAIDER ALMAWLAH, HADEEL ALAA, SANAA O AL-JELAWI* \\ DNA Research Center, University of Babylon, Babel, Iraq. Email: omranaljelwi@gmail.com
}

Received: 03 July 2017, Revised and Accepted: 28 August 2017

ABSTRACT

Objective: The increasing of antibiotic resistance of Pseudomonas aeruginosa causes serious worldwide infection problems. Hence, the objective of the study was to investigate the antibacterial activity of some plants against multidrug resistance P. aeruginosa isolated from burn-wound infections.

Methods: About 30 burn-wound swab samples taken from hospitalized patients in Al-Hillah Teaching Hospital, Babylon Province. P. aeruginosa isolates were isolated and identified depending on cultural, microbial, and biochemical characteristics. Then, the drug susceptibility was detected using different available antibiotics (8) to select multidrug resistance P. aeruginosa strains for using as test organisms. Three types of plants, including onion bulbs (Allium cepa), leaves of mint (Mentha asiatica), and outer peel of pomegranate (Punica granatum), were extracted by three types of solvent. The plant extracts were tested as antimicrobial substances.

Results: About 9 samples were found positive by causing bacterial infection who presented invasive burn-wound infection from both sex and average age of 9 to 45 years. P. aeruginosa was found to be the most common isolates, 10 samples out of 30 samples. The most of multidrug resistance $P$. aeruginosa was used as test organisms to investigate the antimicrobial activity of three types of plant extracts. The plant extract of $P$. granatum showed the highest antibacterial activity, followed by A. cepa, and finally, M. asiatica.

Conclusion: From the study, all three studied plants had antibacterial activity against multidrug-resistant $P$. aeruginosa isolated from burn wound. It is a recommendation that natural products can use as therapeutic agents will probably not elicit resistance in bacteria. More research must continue to isolate and purify the active components and applied in experimental animal models.

Keywords: Multidrug resistance Pseudomonas aeruginosa, Allium cepa, Mentha asiatica, Punica granatum.

(c) 2017 The Authors. Published by Innovare Academic Sciences Pvt Ltd. This is an open access article under the CC BY license (http://creativecommons. org/licenses/by/4. 0/) DOI: http://dx.doi.org/10.22159/ajpcr.2017.v10i12.21071

\section{INTRODUCTION}

Burn-wound infection due to Pseudomonas aeruginosa poses a significant challenge in terms of graft loss, systemic sepsis, prolonged hospital stay, and even increased mortality. Armour et al. [1] reported on 48 adult patients with gentamicin-resistant $P$. aeruginosa colonization compared with case-matched controls; this cohort required a two-fold increase in grafting procedures as well as an average of 15 days' longer hospital stay. Geyik et al. [2] reported the only specific series to detail the effect of $P$. aeruginosa in children, and they found that $65 \%$ frequency of wound colonization, with systemic sepsis in $7.2 \%$, when associated with bacteremia, was associated with an $80 \%$ mortality. Herbal medicines have been important sources of products for developing countries in treating common infectious diseases and the problems of resistance and side effects of the currently available antimicrobial agents [3]. The World Health Organization estimates that $80 \%$ of the people living in developing countries almost fully depend on traditional herbal medicines in Iraq known as Arabic medicine. This means that approximately 3300 million people use medicinal plants on a regular basis. Medicinal plants used in traditional medicine should be studied for safety [4]. Hence, we use three types of plants which approved their ability as antimicrobial activity against pathogenic bacteria isolated from burn infection, especially against $P$. aeruginosa, onion bulbs (Allium cepa), leaves of mint (Mentha asiatica), and outer peel of pomegranate (Punica granatum).

Each one of the chosen plant extract has special active chemical compound against the specific chemical compound on/or inside pathogenic cell, and onion extract is very effective against $P$. aeruginosa due to flavonoids and polyphenols which has been reported to have a broad spectrum of antibacterial activity [5]. While mint extract includes monoterpenes, mainly menthol, menthone, and their derivatives [6]. Pomegranate peels reported that phenolic compounds are punicalagin isomers, ellagic acid derivatives, and anthocyanins [7].

The objective of the study was to investigate the antimicrobial activities of three solvent extracts of selected Iraqi plant against multi-resistant $P$. aeruginosa isolated from burns and wounds.

\section{MATERIALS AND METHODS}

\section{$P$. aeruginosa isolation and identification}

About 30 burn-wound swaps were taken from both male and female burned patients, and average age 9-40 years, from a burn unit of teaching AL-Hillah Hospital, Babylon Provence, Iraq, during September 2016-January 2017. All specimens were inoculated on $5 \%$ blood agar, MacConkey agar, and Chocolate agar plates and incubated overnight at $37^{\circ} \mathrm{C}$ aerobically. The sample was also put into liquid media (Brain Heart Infusion broth) and was subcultured after overnight incubation onto blood agar and MacConkey agar. Bacterial pathogens were identified by conventional biochemical methods according to standard microbiological techniques [8]. Antimicrobial susceptibility was performed on Mueller-Hinton agar by the standard disk diffusion method [9]. The antibiotics tested for bacterial isolates were: Ciprofloxacin (Cip10), amikacin (AK30), chloramphenicol (C30), tetracycline (T30), oxacillin (Ox1), Cip10, trimethoprim (Tmp5), and doxycycline (Do30). The inhibition zone diameter ( $\mathrm{mm}$ ) of antibacterial activities was calculated.

\section{Preparation of plant extracts}

Three plant samples were used in this study; peel of pomegranate, onion bulbs, and mint leaves were purchased from the local markets. 
The plants were classified by specialists in the Botanical Garden at the University of Babylon. These plants were air-dried at room temperature, ground to powder with a mechanical grinder.

\section{Aqueous extraction using hot water}

$20 \mathrm{~g}$ of the weighed plant powder was soaked in $100 \mathrm{ml}$ of hot boiled water for $24 \mathrm{~h}$.The plant extract was separated from the plant solid residue using filter paper with vacuum, then centrifuges and the supernatant filtered using Whatman filter paper No.1. The filtrate was concentrated by a rotary evaporator (rotavapor R300) at $40^{\circ} \mathrm{C}$. The concentrated extract was dried to obtain an extract powder [10]. The powdered was stored in clean containers at $4^{\circ} \mathrm{C}$ for further analysis.

\section{Alcoholic extraction}

Alcoholic extracts were prepared using two solvents such as ethanol and methanol. The plant powder ( $50 \mathrm{~g}$ ) was soaked in $250 \mathrm{ml}$ of $99.9 \%$ for each ethanol or methanol at room temperature for $24 \mathrm{~h}$. The extracts were separated from the other solid plant residues using filter paper with vacuum, and then, it was centrifuged, and the supernatants were filtered using Whatman filter paper No.1. The filtrates were concentrated using a rotary evaporator (rotavapor R300) at $40^{\circ} \mathrm{C}$. The concentrated extracts were dried to obtain the extract powders $[10,11]$. These powdered were stored in clean containers at $4^{\circ} \mathrm{C}$ for further analysis.

\section{Preparation of the stock solutions and dilutions}

A $15 \mathrm{~g}$ of each plant extract powder was dissolved in $50 \mathrm{ml}$ sterile hotdistilled water to prepare the stock solution $(200 \mathrm{mg} / \mathrm{ml})$. While the ethanol extract was firstly dissolved in $1 \mathrm{ml}$ of $99.9 \%$ ethanol due to it was insoluble in water and it was oily nature. Then, diluted in sterile distilled water to give an ethanolic stock solution. All stock solutions were filtrated by Whatman filter paper No. 1 and then by Millipore filter membrane $(0.45 \mu \mathrm{m})$ for sterilization. Different dilution frequencies $(50,100$, and $150 \mathrm{mg} / \mathrm{ml})$ were made with sterile distilled water.

\section{Antibacterial activity determination}

The antibacterial activity of the crude extracts against $P$. aeruginosa was determined by the agar-well diffusion method [12,13] using MullerHinton agar plates. Bacterial suspension $\left(10^{5} \mathrm{CFU} / \mathrm{ml}\right)$ was made, and then, the Muller-Hinton plates were streaked with a bacterial suspension using sterile swab. After that, the wells were made with a diameter of $6 \mathrm{~mm}$ by punched aseptically with a sterile cork borer (No. 6). Approximately $50 \mu \mathrm{l}$ of the crude extract at different concentrations 50,100 , and $150 \mathrm{mg} / \mathrm{ml}$ were loaded into the wells, and the negative control was used a sterile distilled water, in triplicate. One an hour prediffusion time was allowed, after that, the plates were incubated at $37^{\circ} \mathrm{C}$ for $18 \mathrm{~h}$.The diameter of inhibition zones was measured in millimeter and calculated the mean of triplicate results $[14,15]$

\section{RESULT AND DISCUSSION}

\section{Bacterial isolation and identification}

The bacterial isolates (9) were recovered from only 9 burn-wound swabs out of 30 swabs that indicate $30 \%$ of examined burn patients had invasive burn-wound infections. These results are consistent with the previous studies [16-18] who showed that the burn-wound infections are one of the most important and potentially serious issues that occur in the acute period following injury. Furthermore, Raja and Singh [9] demonstrated that the infectious complications are considered a major cause of morbidity and mortality and the type and amount of microorganisms onto and into the injured tissues influence wound healing. In the present study, the most commonly isolated organisms from burning patients were $P$. aeruginosa identified by conventional biochemical methods according to standard microbiological techniques [8] and using the specific chromagar for P. aeruginosa identification.

\section{Antimicrobial susceptibility testing}

Antibacterial susceptible of pseudomonad isolates was detected to determine the multidrug-resistant $P$. aeruginos $a$ isolates. The test was performed by disc diffusion method with different antibiotic discs. The results showed that all Pseudomonas isolates appeared multidrug resistant for all used antibiotics, including $0 \times 1, \mathrm{C} 30, \mathrm{~T} 30, \mathrm{Tmp} 5$, and Do30. However, it had moderate resistance to AK30 and Cip10 as shown in Fig. 1. These results were consistent with the previous studies [17-19]. Increasing resistance to various anti-Pseudomonas agents has been reported worldwide, and this poses a serious problem in therapeutic management of the bacterial infections [17,20]. Furthermore, our results explained that most of the isolates were resistant to many antibiotics.

\section{Antibacterial activity of plant extracts against $P$. aeruginosa}

Agar well diffusion method was used for antibacterial activity determination of aqueous, ethanolic, and methanolic extracts of plants, including outer peel of pomegranate (P. granatum), onion bulbs (A. серa), and mint leaves (M. asiatica). Quantitative evaluation of this activity was carried out against $P$. aeruginosa by measuring of inhibition zone surrounded the wells containing the extract.

As shown in Table 1, plant extracts had antibacterial activity against $P$. aeruginosa with clear differentiation among the extracts depending on the concentration of the extract, type of solvent, and type of plant.

The results show high activity to all ethanolic extract of three plant extracts than methanolic and water extracts as shown in Tables 1-3 due to the ability of ethanol to solve solid organic compounds and liberate all chemical components rather than other solvent used in the present study. Peel of P. granatum (Table 1) showed the highest antipseudomonad activity than other plants in all of the concentrations. The highest concentration of peel of P. granatum extract $(200 \mathrm{mg} / \mathrm{ml})$ appeared highest inhibition zones for all types of extraction methods (38 $\mathrm{mm}$ for ethanolic extract, $36 \mathrm{~mm}$ for methanolic extract and $22 \mathrm{~mm}$ for the water extract). Peel of $P$. granatum contains substantial amounts of polyphenols such as ellagic tannins, ellagic acid, and gallic acid, which have antimicrobial activity [21]. These results were in agreement with Hayrapetyan et al. [22] who reported that the presence of two pure compounds commonly found in the pomegranate-peel extract, namely, ellagic acid and gallic acid. While other study revealed that the phenolic compounds of pomegranate juice are punicalagin isomers, ellagic acid derivatives, and anthocyanins [23]. Ahmad and Beg [24] reported that the phytochemical components found in the alcoholic extract of pomegranate are alkaloid, flavonoid, glycoside, phenol, and tannin. The results of antimicrobial activity of the peel ethanolic extract of $P$. granatum were in agreement with the study of Oskay et al. [25] who recorded $16 \mathrm{~mm}$ inhibition zone diameter against $P$. aeruginosa.

The methanolic extract showed lower action than the ethanolic extract as antibacterial agents. This may be due to little diffusion properties of the extract in the agar or because fresh plants contain

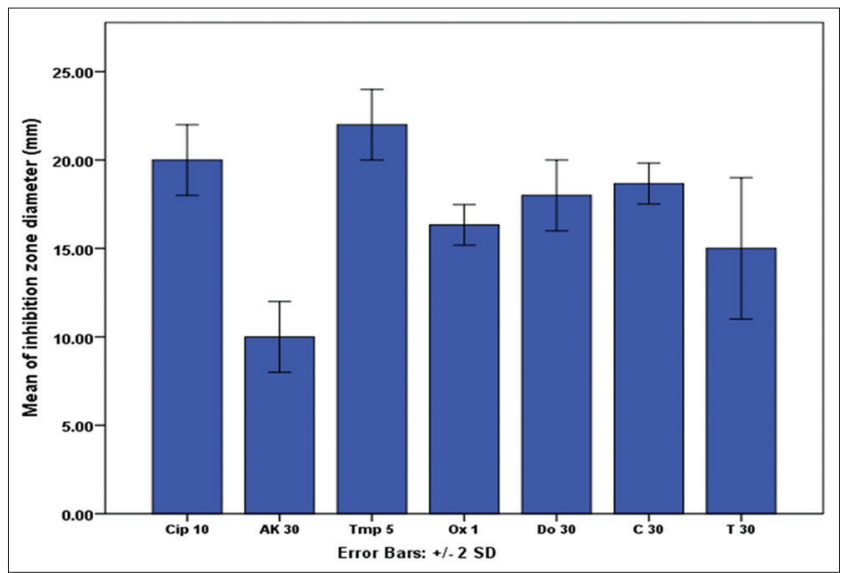

Fig. 1: Multidrug-resistant Pseudomonas aeruginosa isolated from burn-wound infections 
Table 1: Antibacterial activity of $P$. granatum peel extract against multidrug-resistant $P$. aeruginosa isolated from burn wound

\begin{tabular}{|c|c|c|c|c|c|c|}
\hline \multirow[t]{2}{*}{ Types of extract } & \multirow[t]{2}{*}{ Isolate } & \multicolumn{5}{|c|}{ Inhibition zone diameter $\mathrm{mm} \pm \mathrm{SD}$} \\
\hline & & $200 \mathrm{mg} / \mathrm{ml}$ & $150 \mathrm{mg} / \mathrm{ml}$ & $100 \mathrm{mg} / \mathrm{ml}$ & $50 \mathrm{mg} / \mathrm{ml}$ & Control \\
\hline \multirow[t]{8}{*}{ EtOH } & P1 & $38.000 \pm 1.000$ & $35.000 \pm 1.000$ & $30.666 \pm 0.577$ & $27.666 \pm 0.577$ & 0.00 \\
\hline & P3 & $35.000 \pm 1.000$ & $34.666 \pm 1.577$ & $31.000 \pm 1.000$ & $25.000 \pm 1.000$ & 0.00 \\
\hline & $\mathrm{P} 4$ & $30.666 \pm 1.577$ & $20.666 \pm 1.157$ & $15.333 \pm 0.577$ & $16.000 \pm 1.000$ & 0.00 \\
\hline & P5 & $37.666 \pm 1.577$ & $33.333 \pm 1.567$ & $28.666 \pm 1.577$ & $21.666 \pm 1.577$ & 0.00 \\
\hline & P6 & $31.000 \pm 1.000$ & $30.333 \pm 1.577$ & $24.000 \pm 1.000$ & $20.666 \pm 1.577$ & 0.00 \\
\hline & P7 & $40.666 \pm 1.577$ & $35.666 \pm 0.577$ & $31.333 \pm 1.156$ & $25.000 \pm 1.000$ & 0.00 \\
\hline & P8 & $38.000 \pm 1.000$ & $35.333 \pm 1.577$ & $29.000 \pm 1.000$ & $27.666 \pm 1.577$ & 0.00 \\
\hline & P9 & $40.333 \pm 1.577$ & $35.666 \pm 1.577$ & $31.666 \pm 1.577$ & $26.666 \pm 1.156$ & 0.00 \\
\hline \multirow[t]{8}{*}{$\mathrm{MeOH}$} & $\mathrm{P} 1$ & $36.333 \pm 1.577$ & $33.000 \pm 1.000$ & $29.666 \pm 1.527$ & $20.000 \pm 1.000$ & 0.00 \\
\hline & $\mathrm{P} 2$ & $34.333 \pm 1.527$ & $30.666 \pm 1.577$ & $31.000 \pm 1.000$ & $24.000 \pm 1.000$ & 0.00 \\
\hline & P3 & $37.333 \pm 1.577$ & $32.666 \pm 0.577$ & $24.333 \pm 1.577$ & $15.666 \pm 1.527$ & 0.00 \\
\hline & $\mathrm{P} 4$ & $32.666 \pm 0.577$ & $32.666 \pm 1.577$ & $30.000 \pm 1.000$ & $12.000 \pm 1.000$ & 0.00 \\
\hline & P5 & $36.000 \pm 1.000$ & $31.000 \pm 1.000$ & $29.333 \pm 0.577$ & $15.333 \pm 0.333$ & 0.00 \\
\hline & P6 & $34.666 \pm 1.577$ & $33.666 \pm 1.577$ & $30.333 \pm 1.527$ & $20.666 \pm 1.556$ & 0.00 \\
\hline & P8 & $35.333 \pm 0.333$ & $33.333 \pm 1.333$ & $25.666 \pm 0.577$ & $20.333 \pm 1.333$ & 0.00 \\
\hline & P9 & $38.333 \pm 1.577$ & $35.000 \pm 1.000$ & $30.000 \pm 1.000$ & $24.666 \pm 1.527$ & 0.00 \\
\hline \multirow[t]{9}{*}{ Aquas } & P1 & $22.000 \pm 1.000$ & $20.666 \pm 0.577$ & $16.000 \pm 1.000$ & $11.666 \pm 0.577$ & 0.00 \\
\hline & $\mathrm{P} 2$ & $21.333 \pm 0.527$ & $18.000 \pm 1.000$ & $18.333 \pm 0.577$ & $12.666 \pm 0.577$ & 0.00 \\
\hline & P3 & $26.333 \pm 0.577$ & $22.000 \pm 1.000$ & $19.666 \pm 0.577$ & $9.666 \pm 1.527$ & 0.00 \\
\hline & $\mathrm{P} 4$ & $21.333 \pm 0.577$ & $20.666 \pm 0.577$ & $20.000 \pm 1.000$ & $18.333 \pm 0.577$ & 0.00 \\
\hline & P5 & $20.000 \pm 1.000$ & $18.333 \pm 0.577$ & $12.666 \pm 0.577$ & 0.00 & 0.00 \\
\hline & P6 & $20.000 \pm 1.000$ & $15.333 \pm 0.577$ & $10.000 \pm 1.000$ & 0.00 & 0.00 \\
\hline & P7 & $20.666 \pm 0.577$ & $14.333 \pm 0.577$ & $10.666 \pm 0.577$ & $6.666 \pm 0.577$ & 0.00 \\
\hline & P8 & $18.333 \pm 0.577$ & $14.000 \pm 1.000$ & $11.666 \pm 1.527$ & 0.00 & 0.00 \\
\hline & P9 & $22.666 \pm 0.577$ & $18.666 \pm 1.577$ & $14.333 \pm 1.000$ & $12.666 \pm 0.577$ & 0.00 \\
\hline
\end{tabular}

SD: Standard deviation, P. granatum: Punica granatum, P. aeruginosa: Pseudomonas aeruginosa

active substances which may be affected, insoluble, or attributed by the used solvent [5].

Water extract of pomegranate even when it less active than alcoholic solvent still gives obvious $22 \mathrm{~mm}$ inhibition zone diameter that means the extract seems to be thermostable because of using hot-water in plant metabolite extraction. These results were consistent with AlZoreky who found the inhibition zone diameters were ranged from 13 to $17 \mathrm{~mm}$ [7], whereas, the other study [23] found that the inhibition zone diameter was lower (10-40 $\mathrm{mm})$.

The water extract, in the present study, showed lower activity than other extracts that may be due to water extracted less phenolic contents where the phenolic groups are the active component against microbial growth [26]. The effect of the lowest concentration (50 mg/ml) of $P$. granatum of all extractions solvent were still higher than other plant extracts that may be referred to the P. granatum extract containing high amounts of active phenolic contents against microbial growt [27].

The antibacterial activity of onion (A. cepa) extract (Table 2) can be attributed to the presence of flavonoids and polyphenols which has been reported to have a broad spectrum of antibacterial activity [28]. Furthermore, the polyphenols of plants have been reported to have antibacterial activity [29]. In the present study, the onion ethanolic extract showed inhibition zone about $30 \mathrm{~mm}$ at $200 \mathrm{mg} / \mathrm{ml}$ concentration. These zones gradually reduced with decreasing of concentration until $50 \mathrm{mg} / \mathrm{ml}$ which showed no inhibition zone. While the methanolic extract showed high activity than ethanolic one, with inhibition zone was 29,25 , and $18 \mathrm{~mm}$ at concentration 150,100 , and $50 \mathrm{mg} / \mathrm{ml}$, respectively. That means the methanol solvent is the best solvent for phenolic content extraction, which has antibacterial activity as reported in the study of Hendrich [29]. These results were in agreement with the previous studies [30] which reported the inhibition zone was 29, 26, 25, and $24 \mathrm{~mm}$ at concentrations $1000,500,200$, and $100 \mathrm{mg} / \mathrm{ml}$, respectively. Furthermore, it found the antibacterial activity against pseudomonad bacteria of the onion-water extract was $23,18,16$, and $14 \mathrm{~mm}$ at concentrations 1000, 500, 200, and $100 \mathrm{mg} / \mathrm{ml}$, respectively. While in the present study, we showed different results which were lower than ethanolic and methanolic extracts with 20 and $13 \mathrm{~mm}$ at 200 and $150 \mathrm{mg} / \mathrm{ml}$ concentration, respectively. However, they showed no inhibition zone at concentrations 100 and $50 \mathrm{mg} / \mathrm{ml}$. That is because of water is more polarity than alcoholic solvent, so low level of phenolic and alkaloid compounds was extracted which disruption of the cell membrane [31-35].

M. asiatica leaves extract (Table 3) also shows most antimicrobial activity in the ethanolic extract than methanol and water extract with a range of inhibition zones $36,30,25$, and $18 \mathrm{~mm}$ at concentrations $200,150,100$, and $50 \mathrm{mg} / \mathrm{ml}$, respectively. These results agreed with the findings of El-Taweil [5] but less activity (3.3 and $7.3 \mathrm{~mm}$ inhibition zone at 200 and $100 \mathrm{mg} / \mathrm{ml}$ concentration, respectively). The principle active components of peppermint $M$. asiatica are monoterpenes, mainly menthol, menthone, and their derivatives (e.g., isomenthone, neomenthol, acetyl menthol, and pulegone). These essential oils dilate blood vessels and inhibit bacteria. Especially, menthol has a broad-spectrum antibacterial activity [36].

Also, the methanolic peppermint extract was higher antibacterial activity against test organisms than water extract with $30 \mathrm{~mm}$ inhibition zone at $200 \mathrm{mg} / \mathrm{ml}$ concentration and $19 \mathrm{~mm}$ at $50 \mathrm{mg} / \mathrm{ml}$. The results of the present study were higher than other study [5] which used chloroform as extraction solvent instead methanol to solve peppermint that showed $9.2 \mathrm{~mm}$ inhibition zone at $150 \mathrm{mg} / \mathrm{ml}$ and $14.2 \mathrm{~mm}$ at $100 \mathrm{mg} / \mathrm{ml}$ of chloroform or methanol increased the suspended higher compounds.

Water extract of $M$. asiatica also has moderately active against $P$. aeruginosa where alcoholic solvents are more effective, and results show an inhibition zone range $21,19,13$, and $9 \mathrm{~mm}$ at concentrations $200,150,100$, and $50 \mathrm{mg} / \mathrm{ml}$, respectively, which was the lowest effect on $P$. aeruginosa than other plants. 
Table 2: Antibacterial activity of $A$. cepa bulbs extract against multidrug-resistant $P$. aeruginosa isolated from burn wound

\begin{tabular}{|c|c|c|c|c|c|c|}
\hline \multirow[t]{2}{*}{ Type of extract } & \multirow[t]{2}{*}{ Isolate } & \multicolumn{5}{|c|}{ Inhibition zone $\mathbf{m m} \pm \mathrm{SD}$} \\
\hline & & $200 \mathrm{mg} / \mathrm{ml}$ & $150 \mathrm{mg} / \mathrm{ml}$ & $100 \mathrm{mg} / \mathrm{ml}$ & $50 \mathrm{mg} / \mathrm{ml}$ & Control \\
\hline \multirow[t]{8}{*}{ EtOH } & P1 & $30.000 \pm 1.000$ & $21.333 \pm 0.577$ & $16.000 \pm 1.000$ & 0.00 & 0.00 \\
\hline & P3 & $29.666 \pm 0.577$ & $25.666 \pm 0.577$ & $14.666 \pm 0.577$ & $10.000 \pm 1.000$ & 0.00 \\
\hline & $\mathrm{P} 4$ & $33.000 \pm 1.000$ & $24.000 \pm 1.000$ & $20.666 \pm 0.577$ & $10.000 \pm 1.000$ & 0.00 \\
\hline & P5 & $38.666 \pm 1.577$ & $34.000 \pm 1.000$ & $30.000 \pm 1.000$ & $21.666 \pm 0.577$ & 0.00 \\
\hline & P6 & $32.000 \pm 1.000$ & $18.666 \pm 0.577$ & $16.666 \pm 0.577$ & $10.000 \pm 1.000$ & 0.00 \\
\hline & P7 & $30.000 \pm 1.000$ & $21.333 \pm 0.527$ & $16.666 \pm 0.577$ & 0.00 & 0.00 \\
\hline & P8 & $30.000 \pm 1.000$ & $24.000 \pm 1.000$ & $16.000 \pm 0.577$ & 0.00 & 0.00 \\
\hline & P9 & $31.000 \pm 1.000$ & $21.333 \pm 0.527$ & $14.666 \pm 0.577$ & 0.00 & 0.00 \\
\hline \multirow[t]{8}{*}{$\mathrm{MeOH}$} & $\mathrm{P} 1$ & $32.000 \pm 1.000$ & $29.000 \pm 1.000$ & $25.000 \pm 1.000$ & $18.333 \pm 0.527$ & 0.00 \\
\hline & $\mathrm{P} 2$ & $32.666 \pm 1.577$ & $30.666 \pm 1.577$ & $22.000 \pm 1.000$ & $15.000 \pm 1.000$ & 0.00 \\
\hline & P3 & $33.000 \pm 1.000$ & $29.000 \pm 1.000$ & $22.000 \pm 1.000$ & $14.000 \pm 1.000$ & 0.00 \\
\hline & $\mathrm{P} 4$ & $32.333 \pm 1.527$ & $30.000 \pm 1.000$ & $22.333 \pm 1.577$ & 0.00 & 0.00 \\
\hline & P5 & $35.666 \pm 1.577$ & $30.666 \pm 1.577$ & $25.000 \pm 1.000$ & $15.000 \pm 1.000$ & 0.00 \\
\hline & P6 & $32.666 \pm 1.577$ & $29.000 \pm 1.000$ & $25.333 \pm 1.527$ & $16.000 \pm 1.000$ & 0.00 \\
\hline & P8 & $30.000 \pm 1.000$ & $27.000 \pm 1.000$ & $21.333 \pm 0.527$ & $18.666 \pm 0.577$ & 0.00 \\
\hline & P9 & $32.000 \pm 1.000$ & $29.000 \pm 1.000$ & $25.001 \pm 1.000$ & $18.666 \pm 0.527$ & 0.00 \\
\hline \multirow[t]{9}{*}{ DW } & P1 & $20.000 \pm 1.000$ & $13.666 \pm 0.577$ & 0.00 & 0.00 & 0.00 \\
\hline & $\mathrm{P} 2$ & $19.000 \pm 1.000$ & $15.000 \pm 1.000$ & 0.00 & 0.00 & 0.00 \\
\hline & P3 & $24.000 \pm 1.000$ & $16.666 \pm 0.577$ & $6.666 \pm 0.577$ & $2.666 \pm 0.527$ & 0.00 \\
\hline & $\mathrm{P} 4$ & $24.333 \pm 1.527$ & $16.000 \pm 1.000$ & $10.666 \pm 1.577$ & 0.00 & 0.00 \\
\hline & P5 & $34.000 \pm 1.000$ & $29.333 \pm 1.527$ & $19.666 \pm 1.577$ & $10.333 \pm 0.527$ & 0.00 \\
\hline & P6 & $26.000 \pm 1.000$ & $20.333 \pm 0.527$ & $9.666 \pm 0.577$ & 0.00 & 0.00 \\
\hline & P7 & $20.333 \pm 0.527$ & $13.666 \pm 0.577$ & $6.66 \pm 0.577$ & 0.00 & 0.00 \\
\hline & P8 & $18.666 \pm 0.577$ & $14.666 \pm 0.577$ & 0.00 & 0.00 & 0.00 \\
\hline & P9 & $20.000 \pm 1.000$ & $13.666 \pm 0.577$ & 0.00 & 0.00 & 0.00 \\
\hline
\end{tabular}

SD: Standard deviation, P. aeruginosa: Pseudomonas aeruginosa, A. cepa: Allium cepa

Table 3: Antibacterial activity of $M$. asiatica extract against multidrug-resistant $P$. aeruginosa isolated from burn wound

\begin{tabular}{|c|c|c|c|c|c|c|}
\hline \multirow[t]{2}{*}{ Types of extract } & \multirow[t]{2}{*}{ Isolate } & \multicolumn{5}{|c|}{ Inhibition zone $\mathrm{mm} \pm \mathrm{SD}$} \\
\hline & & $200 \mathrm{mg} / \mathrm{ml}$ & $150 \mathrm{mg} / \mathrm{ml}$ & $100 \mathrm{mg} / \mathrm{ml}$ & $50 \mathrm{mg} / \mathrm{ml}$ & Control \\
\hline \multirow[t]{9}{*}{$\mathrm{EtOH}$} & $\mathrm{P} 1$ & $36.333 \pm 1.577$ & $30.333 \pm 1.577$ & $25.000 \pm 1.000$ & $18.666 \pm 0.577$ & 0.00 \\
\hline & $\mathrm{P} 2$ & $37.000 \pm 1.000$ & $33.666 \pm 1.577$ & $26.000 \pm 1.000$ & $15.000 \pm 1.000$ & 0.00 \\
\hline & P3 & $30.000 \pm 1.000$ & $18.666 \pm 1.577$ & $19.000 \pm 1.000$ & $10.666 \pm 1.577$ & 0.00 \\
\hline & P4 & $39.000 \pm 1.000$ & $35.333 \pm 1.527$ & $30.666 \pm 1.577$ & $29.000 \pm 1.000$ & 0.00 \\
\hline & P5 & $30.666 \pm 1.577$ & $30.666 \pm 1.577$ & $25.000 \pm 1.000$ & $13.333 \pm 0.577$ & 0.00 \\
\hline & P6 & $36.666 \pm 1.577$ & $35.666 \pm 1.577$ & $31.666 \pm 0.577$ & $26.333 \pm 0.577$ & 0.00 \\
\hline & P7 & $36.666 \pm 1.577$ & $30.333 \pm 1.577$ & $25.333 \pm 1.577$ & $17.000 \pm 1.000$ & 0.00 \\
\hline & P8 & $36.000 \pm 1.000$ & $30.333 \pm 0.577$ & $25.000 \pm 1.000$ & $18.333 \pm 0.577$ & 0.00 \\
\hline & P9 & $35.333 \pm 1.527$ & $30.000 \pm 1.000$ & $25.666 \pm 0.577$ & $18.000 \pm 1.000$ & 0.00 \\
\hline \multirow[t]{7}{*}{$\mathrm{MeOH}$} & $\mathrm{P} 1$ & $30.000 \pm 1.000$ & $27.000 \pm 1.000$ & $20.666 \pm 1.577$ & $19.666 \pm 1.577$ & 0.00 \\
\hline & $\mathrm{P} 2$ & $30.666 \pm 1.577$ & $25.000 \pm 1.000$ & $19.333 \pm 0.527$ & $15.666 \pm 0.577$ & 0.00 \\
\hline & P3 & $35.666 \pm 1.577$ & $30.000 \pm 1.000$ & $25.000 \pm 1.000$ & $15.666 \pm 1.527$ & 0.00 \\
\hline & $\mathrm{P} 4$ & $37.000 \pm 1.000$ & $31.000 \pm 1.000$ & $28.666 \pm 0.527$ & $25.000 \pm 1.000$ & 0.00 \\
\hline & P5 & $28.666 \pm 0.577$ & $27.000 \pm 1.000$ & $20.00 \pm 1.000$ & $17.333 \pm 0.577$ & 0.00 \\
\hline & P8 & $30.666 \pm 1.577$ & $27.333 \pm 0.577$ & $20.000 \pm 1.000$ & $19.000 \pm 1.000$ & 0.00 \\
\hline & P9 & $30.000 \pm 1.000$ & $27.000 \pm 1.000$ & $18.666 \pm 0.577$ & $19.333 \pm 0.527$ & 0.00 \\
\hline \multirow[t]{9}{*}{ DW } & $\mathrm{P} 1$ & $21.666 \pm 0.577$ & $19.000 \pm 1.000$ & $13.666 \pm 0.577$ & $9.000 \pm 1.000$ & 0.00 \\
\hline & $\mathrm{P} 2$ & $25.000 \pm 1.000$ & $18.666 \pm 0.577$ & $16.333 \pm 0.527$ & 0.00 & 0.00 \\
\hline & P3 & $22.333 \pm 0.577$ & $20.666 \pm 0.577$ & $15.333 \pm 0.527$ & 0.00 & 0.00 \\
\hline & $\mathrm{P} 4$ & $27.000 \pm 1.000$ & $20.666 \pm 1.577$ & $10.666 \pm 0.577$ & $9.666 \pm 0.577$ & 0.00 \\
\hline & P5 & $19.666 \pm 0.577$ & $18.666 \pm 0.577$ & $14.333 \pm 0.577$ & 0.00 & 0.00 \\
\hline & P6 & $20.000 \pm 1.000$ & $15.666 \pm 0.577$ & $9.666 \pm 0.577$ & $5.666 \pm 0.577$ & 0.00 \\
\hline & P7 & $21.333 \pm 0.577$ & $19.666 \pm 0.577$ & $11.666 \pm 0.527$ & $9.333 \pm 0.577$ & 0.00 \\
\hline & P8 & $23.000 \pm 1.000$ & $19.666 \pm 0.577$ & $13.666 \pm 0.577$ & $9.666 \pm 0.577$ & 0.00 \\
\hline & P9 & $24.000 \pm 1.000$ & $18.666 \pm 0.577$ & $13.666 \pm 0.577$ & $9.000 \pm 1.000$ & 0.00 \\
\hline
\end{tabular}

M. asiatica: Mentha asiatica, SD: Standard deviation, P. aeruginosa: Pseudomonas aeruginosa

The result of the study revealed that all solvents, actively effect against the $P$. aeruginosa that are a common cause of infections. $M$. asiatica shows significant activity as because of their leaves contain many potent compounds such as menthol, menthone, menthyl acetate, menthofuran, and limnone [37].

\section{CONCLUSION}

From the study, all three studied plants had antibacterial activity against multidrug-resistant $P$. aeruginosa isolated from burn wound. P. granatum showed the highest antibacterial activity, followed by 
A. сера, and finally, M. asiatica. It is a recommendation that natural products can use as therapeutic agents will probably not elicit resistance in bacteria. More research must continue to isolate and purify the active components and applied in experimental animal models.

\section{REFERENCES}

1. Armour AD, Shankowsky HA, Swanson T, Lee J, Tredget EE. He impact of nosocomially-acquired resistant Pseudomonas aeruginosa infection in a burn unit. J Trauma 2007;63(1):164-71

2. Geyik MF, Aldemir M, Hosoglu S, Tacyildiz HI. Epidemiology of burn unit infections in children. Am J Infect Control 2003;31:342-6.

3. Kianbakht S, Jahaniani F. Evaluation of antibacterial activity of Tribulus terrestris L. growing in Iran. Iran J Pharm Ther 2003;2:22-4.

4. Eloff JN. Which extractant should be used for the screening and isolation of antimicrobial components from plants? J Ethnopharmacol 1998;60(1):1-8.

5. El-Taweil M. Assessment of antimicrobial activity of onion extract (Alliumcepa) on Staphylococcus aureus; In vitro study. Int Conf Chem Agric Med Sci 2014;29(30):16-7.

6. Hayyan I, Al-Taweil M. Antimicrobial effect of mint essential oils on some pathogenic bacteria. Int J Life Sci Res 2014;2(4):90-3.

7. Al-Zoreky NS. Antimicrobial activity of pomegranate (Punica granatum L.) fruit peels. Int J Food Microbiol 2009;134(3):244-8.

8. Forbes BA, Sahm DF, Weissfeld AS. Bailley and Scott Diagnostic Microbiology. 10 $10^{\text {th }}$ ed. London: Mosby; 1998.

9. Raja NS, Singh NN. Antimicrobial susceptibility pattern of clinical isolates of Pseudomonas aeruginosa in a tertiary care hospital. J Microbiol Immunol Infect 2007;40(1):45-9.

10. Okigbo RN, Mmeka EC. Antimicrobial effects of three tropical plant extracts on Staphylococcus aureus, Escherichia coli and Candida albicans. Afr J Tradit Complement Altern Med 2008;5:226-9.

11. Sama Fonkeng L, Mouokeu RS, Tume C, Njateng GS, Kamcthueng MO, Ndonkou NJ, et al. Anti - Staphylococcus aureus activity of methanol extracts of 12 plants used in Cameroonian folk medicine. BMC Res Notes 2015;8:710.

12. Irobi ON, Moo-Young M, Anderson WA, Daramola SO. Antimicrobial activity of bark extracts of Bridelia ferruginea (Euphorbiaceae). J Ethnopharmacol 1994;43:185-90.

13. Omran R. Production of antimicrobial and anticancer from featherkeratinolytic Nocardiopsis sp. 28ROR as a novel strain using feather meal medium. Int J Pharm Pharm Sci 2017;9(3):175-9.

14. Magaldi S, Mata-Essayag S, Hartung de Capriles C, Perez C, Colella MT, Olaizola C, et al. Well diffusion for antifungal susceptibility testing. Int J Infect Dis 2004;8:39-45.

15. Smânia EF, Valgas C, De Souza SM. Screening methods todetermine antibacterial activity of natural products. Braz J Microbiol 2007;38(2):369-80.

16. Mooney DP, Gamelli RL. Sepsis following thermal injury. Compr Ther 1989;15:22-9.

17. Radi RO, Rahman FM. Study of effects ethidium bromide, SDS and elevated temperature on stability of multiple antibiotic resistance plasmids of Pseudomonas aeruginosa. Iraqi J Biotech 2010;9(4):797-11".

18. Omran R. The virulence factors of Pseudomonas aeruginosa isolated from eye infections. J Karbala Univ 2005;5:112-1.
19. Kehinde AO, Ademola SA, Okesola AO, Oluwatosin OM. Pattern of bacterial pathogens in burn wound infections in Ibadan, Nigeria. Ann Burns Fire Dis 2004; 17:348-55.

20. Brown PD, Izundu A. Antibiotic resistance in clinical isolates of Pseudomonas aeruginosa in Jamica. Rev Panam Salud Publica 2004;16(2):125-30.

21. Negi PS, Jayaprakasha GK, Jena BS. Antioxidant and antimutagenic activities of pomegranate peel extracts. Food Chem 2003;80:393-7.

22. Hayrapetyan H, Hazeleger WC, Beumer RR. Inhibition of Listeria monocytogenes by pomegranate (Punica granatum) peel extract in meat pat'e at different temperatures. Food Control 2012;23:66-72.

23. Li Y, Guo C, Yang J, Wei J, Xu J, Cheng S. Evaluation of antioxidant properties of pomegranate peel extract in comparison with pomegranate pulp extract. Food Chem 2006;96(2):254-60.

24. Ahmad I, Beg AZ. Antimicrobial and phytochemical studies on 45 Indian medicinal plants against multi-drug resistant human pathogens. J Ethnopharmacol 2001;74(2):113-23.

25. Oskay M, Oskay D, Kalyoncu F. Activity of some plant extracts against multi-drug resistant human pathogens. Iran J Pharm Res 2009;8(4):293-300.

26. Nuamsetti T, Dechayuenyong P, Tantipaibulvut S. Antibacterial activity of pomegranate fruit peels and arils. Sci Asia 2012;38:319-22

27. Voravuthikunchai S, Lortheeranuwat A, Jeeju W, Sririrak T, Phongpaichit S, Supawita T. Effective medicinal plants against enterohaemorrhagic Escherichia coli O157:H7. J Ethnopharmacol 2004;94(1):49-54

28. Grover A, Bhandari B, Nishant R. Antimicrobial activity of medicinal plants - Azadirachta indica A. Juss, Allium cepa L. and Aloe vera L. Int J Pharm Tech Res 2011;3(2):1059-65.

29. Hendrich A. Flavonoid-membrane interactions: Possible consequences for biological effects of some polyphenolic compounds. Acta Pharmacol Sin 2006;27(1):27-40.

30. Ani V, Varadaj M, Naidu K. Antioxidant and antibacterial activities of polyphenolic compounds from bitter cumin (Cuminum rigrum L.). Eur Food Res Technol 2006;224(1):109-15.

31. Perez C, Pauli M, Bazerque P. An antibiotic assay by the agar-well diffusion method. Acta Biol Med Exp 1990;15:113-5.

32. Al-Marzook FA, Omran R. Cytotoxic activity of alkaloid extracts of different plants against breast cancer cell line. Asian J Pharm Clin Res 2017;10(7):168-71.

33. Omran R, Al-Taee ZM, Hashim HO, AL-Jassani MJ. Extraction of phenolic compounds as antioxidant from some plants and their cytotoxic activity against breast cancer cell line. Asian J Pharm Clin Res 2017;10(7):168-71.

34. Al-Marzook FA, Omran R. Cytotoxic activity of alkaloid extracts from three Iraqi plants against breast cancer cell line. Asian J Pharm Clin Res 2017;10(9):78-81.

35. Adebayo OL, Edwin BA. Solvent extract of different plants of Phyllanthus niruri show potent growth inhibition against six human pathogenic bacteria in vitro. Int J Pharm Pharm Sci 2014;6(7):272-7.

36. Bupesh C, Amutha S, Nandagopal A, Ganeshkumar P, Sureshkumar K, Murali S. Antibacterial activity of Mentha piperita L. (Peppermint) from leaf extracts-a medicinal plant. Acta Agric Slov 2007;89:73-9.

37. Sartoratto A, Machado AL, Delarmelina C, Figueira GM, Duarte MC, Rehder VL. Composition and antimicrobial activity of essential oils from aromatic plants used in Brazil. Braz J Microbiol 2004;34(4):1517-20. 